\title{
Science education and communication
}

\author{
Dennis Ausiello
}

S ince its inception, members of the Association of American Physicians (AAP) have made distinguished contributions as physician-scientists, educators, and clinicians. I would like to speak to you today about two intersecting missions of our Society and profession that I am personally passionate about, and believe require serious stewardship: science education for the development of the physician-scientist, and the important parallel activity of communication to our public and Congress about science and the process of discovery.

Over the past 122 years, AAP members have aspired to create new knowledge about the human condition, and disseminate that knowledge to our students, patients, and public. Our commitment to the education of the physician-scientist has been unswerving, but ever changing. Over the last few decades, our profession has become less art, and more scientific and evidenced based. The study of biology has provided the framework for understanding the function of an organism. It is, in essence, the "theology" of our profession. Using biology alone, it has become rather straightforward to transmit our knowledge of the human organism based on reproducible observation, with a comfort that we are preparing well the next generation of physician-scientists.

As each generation has been steeped in the tradition of scientific inquiry and advanced our understanding of biology, the Academy has unraveled the complexities of human function, and the pharmaceutical industry has produced some extraordinary therapies to treat human disease. Despite this long legacy of progress, I propose that the skill sets and tool kits of our generation will be insufficient to create the next generation of physicianscientists, who must work in a team-ori-

This article is adapted from a presentation at the ASCI/AAP Joint Meeting, April 13-15, 2007, in Chicago, Illinois, USA.

Address correspondence to: Dennis Ausiello, Massachusetts General Hospital, Department of Medicine, 55 Fruit Street, GRB 740, Boston, Massachusetts 02114 USA. Phone: (617) 726-5660; Fax: (617) 724-7441; E-mail: dausiello@partners.org.

Citation for this article: J. Clin. Invest. 117:3128-3130 (2007). doi:10.1172/JCI33385. ented, multidisciplinary arena, and require more rigorous education in a defined scientific discipline.

Biology can no longer be viewed as the science that drives our understanding, but rather, an elegant expression of chemistry, physics, and mathematics, which collectively are needed to provide new insight. We have entered an era where new biological knowledge of human function and its pathology are informed by nontraditional disciplines. The remarkable insights,

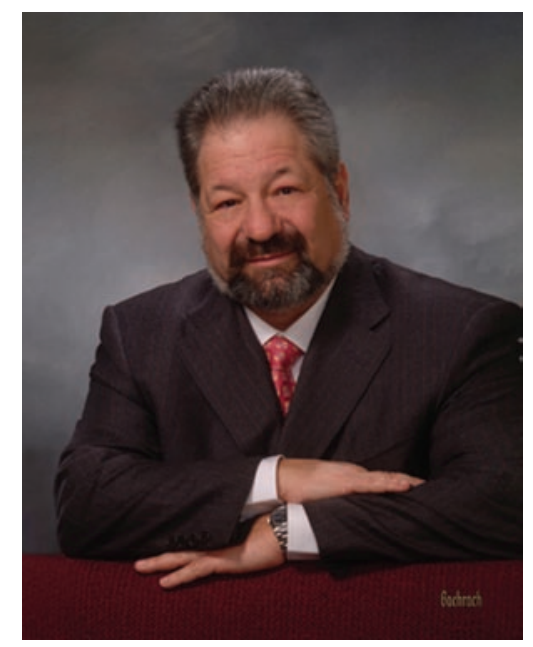

Dennis A. Ausiello, MD, is Chairman of the Department of Medicine at Massachusetts General Hospital and the Jackson Professor of Clinical Medicine at Harvard Medical School. He served as President of the Association of American Physicians from 2006 to 2007.

through reductionism, that have been brought forward in the last century, now demand mathematics, computer science, physics, nanotechnology, imaging, and engineering to assemble that knowledge into a coherent understanding of cells, organs, organisms, and ultimately the full human condition.

Science, in the broadest sense, has become a continuum, so that new insights in, physics, for example, rapidly enlighten a biological process. In 2005, on the eve of its 125 th anniversary, Science magazine published an issue with the 125 most important unanswered questions in science (1). What is remarkable about the list of questions is not their diversity, which ranges from understanding the universe to the human organism, but rather the interdependence of the potential answers across all fields.

If the future requires a much broader understanding of diverse disciplines, a novel and robust educational program must be put in place to prepare the next generation of physician-scientists to meet interdisciplinary goals leading to the understanding of the human organism. We must engage all disciplines in collaborative educational programs to meet these ends. Visionary and creative leadership and properly applied resources are necessary to launch this new educational paradigm. The critical elements of such an educational program in the context of a University should have a logical continuum from undergraduate through postgraduate and professional education. The foundation for a scientific career in biological investigation should start in undergraduate programs. About ten years ago, when I was the Director of the MD/PhD programs at Harvard and MIT, I audited about a dozen biology classes at both universities. Interestingly, the word "human" did not appear in any of the content being taught. Our students were becoming fluent in science, but learning a language that was completely untethered to the understanding of the human organism, an inherent discontinuity that would later continue into their professional education.

Another concern with undergraduate education is the lack of alignment of chemistry and physics with biological processes. In required chemistry courses, for example, there was as much time spent by the future life scientists in learning high temperature chemistry as the principles of enzymology. What is needed today is for chemistry, physics, and mathematics departments to partner with biologists, and collectively teach biologically relevant content in a rigorous way. At my own university, such 
initiatives are now underway. In Spring 2007, a meeting of medical school deans convened to hear about new composite courses in chemistry, physics, and biology as a potential means of satisfying medical school admission requirements. Despite rumblings for rigor and integration in these prerequisites, medical school admission requirements have changed little over the past decade, and in some cases, relaxed. For example, fewer than ten medical schools now require calculus or biostatistics for admission. I do not believe that this is in the best interest of students wishing to become physician-scientists. Another important initiative today by some universities is to weave human biology into the context of rigorous undergraduate science education, with the establishment of Departments of Systems Biology, and Developmental and Regenerative Biology. Systems biology, as Peter Sorger of Harvard Medical School defines it, is the "study of biological processes using a combination of mathematics, computation and empirical observation. The numerical emphasis is important, because only quantitative models have the power to capture dynamic processes involving large numbers of interacting components. The empirical emphasis is also critical because it is only through careful experimentation that models can be validated." Medical schools and academic health centers should partner with systems and developmental biology programs, learning from and informing the content that can be extended from undergraduates to medical students, graduate students, and trainees with professional degrees.

There has been unquestionable success at many medical schools from the parallel training pathways for $\mathrm{MD} / \mathrm{PhD}$ matriculants. Such programs should and will continue to thrive. But they facilitate the development of a relatively small group. About $500 \mathrm{MD} / \mathrm{PhDs}$ graduate from US medical schools each year with an extended education time of 7-10 years. In contrast, 17,000 students graduate each year in the US with the MD degree. At a minimum, we need to train more potential physician scientists, and in the long run, come up with a comprehensive, rigorous program that could perhaps replace the $\mathrm{MD} / \mathrm{PhD}$ programs. Such new programs could be incorporated in extended training for the MD degree. They will require breaking down educational approaches, and assembling them into a coherent and sophisticated learning experience for that subset of students choosing a career in medicine and the science of the human organism.

Physics Laureate David Gross has said "one of the most creative qualities a research scientist can have is the ability to ask the right questions." Our goal as educators should be to produce an MD with an inquiring mind, asking about what we do not know about a disease, and having the tool kits and skill sets to pursue, indeed lead, a level of inquiry to advance our knowledge of the human condition. Such individuals should be the new leaders of what is currently called "translational" research. What will differ from traditional scientific educational programs is the multidisciplinary approach. It will be team oriented, taking advantage of the interdisciplinary nature of future inquiry. It will likely require a slightly longer period of education, perhaps a 5- or 6-year program, and the pursuit of an area in depth, such as genetics. This will allow for diverse expertise to be accumulated within whatever partnerships or teams are ultimately assembled to pursue discovery. While the pursuit of these educational goals should be a University-wide endeavor, it must be led by medical schools and academic health centers, and provided with new resources to complement the traditional training programs for the MD and $\mathrm{PhD}$ degrees. This new educational mandate for those wishing to study the human organism should not be a vehicle to provide a less rigorous scientific opportunity than has traditionally been embedded in the $\mathrm{PhD}$ degree. The next generation of physicianscientists, whatever degree or degrees we impart on them, must be unquestionably credible and credentialed. The focus on the human organism should not be an excuse for warm and fuzzy science.

What are the obligations to the physician scientist in the clinical arena? The training of the physician-scientist does not begin and end in the classroom and laboratory. The greatest inspiration for the inquiring mind of the physician-scientist should be the clinical setting. Unfortunately, as our understanding of the scientific mechanisms causing disease has grown exponentially, the time to discuss them has decreased. In the typical academic hospital today, the level of acuity of patient illness has risen and the length of hospital stay has dramatically fallen, so that discussion is often limited and focused on immediate patient management. It should be truly distressing to see our most talented physi- cian-scientist trainees, well schooled in the classroom and laboratory, with wonderful inquiring minds, enter a busy residency program and see a necessity to suspend intellectual curiosity. "Just get the job done. Get Mrs. Jones as well as possible and out of the hospital." I do not need to inform my AAP colleagues of these issues, nor is this talk meant to ignore the reasons that have led to this point in academic medicine. They have been well documented. But I must say, no matter how creative we are in developing the educational paradigm for the physician scientist, all will be for naught if we do not regain for them their most precious resource: the patient.

While there are no easy solutions to overcome the noninquiring environment generated by pace and acuity in our hospitals, we must develop the opportunity for our residents to ask and discuss what we do not know about a patient's illness. Program directors, chairs of medicine, hospital presidents, and medical school deans have to make the investment necessary to insure that such an environment can exist. What we cannot continue to let happen is the current unintended consequence of the health delivery system, driving the resident even further from the patient. A dialogue with the patient, and about the patient with others, will inevitably revolve around the complexity of the problem, and perhaps provide a pathway to enlightenment. Scientists traditionally relish contradiction, because it is often the source of new insights. "No paradox, no progress," said the great Danish physicist Niels Bohr. The impact of reflective physicians on medical progress is difficult to overstate. The discovery that peptic ulcers can be caused by bacterial infection, the use of steroids to treat rheumatoid arthritis, the identification of Lyme disease, premature atherosclerosis and its link to cholesterol metabolism, are all important medical advances that resulted from physicians' efforts to understand the problems of their own patients combined with astute observation. The physicians responsible for these insights had time for reflection. What has turned out to be the most significant casualty of the current training experience is the disappearance of time to think, in an expansive fashion, about an individual patient. Traditionally, such reflective thinking has been a hallmark of teaching hospitals. It was why physicians came to train and why patients came for treatment. We need to reinstill in our trainees that medicine is more than 
simply the compassionate application of received wisdom, it is also the challenging of old customs, and the development of new insights. With new efforts we can ensure the appropriate training and education of inquiring and competent physicians, rigorously trained in science to understand the complex human organism. This new model of physician-scientist will possess a distinct area of expertise, work in a team of similar individuals with disparate expertise, and with highly differentiated scientists, like physicists, chemists, and computational biologists. All will work together to improve the understanding and quality of our patients' lives.

\section{Communication of Science}

Although its essential importance may seem less obvious than the preparation of physician-scientists, our responsibilities in communicating science and the process of discovery to the public, Congress, and the media are also critical to have public support for the investment in our research activities. Unfortunately, this is a responsibility that we have not been distinguished in carrying out. The times require, more than ever, that we succeed in communicating the path of scientific discovery. Equally important, with the human organism rapidly becoming the major experimental model, we need our patients to understand that they are our partners in discovery. Training new physician-scientists will be a hollow achievement without society's understanding, celebration, and investment in their endeavors. Our dialogue with patients and the public has rarely included a description of how new medical knowledge is achieved, and what it means. Indeed, by any analysis, the American public is scientifically ignorant. With a void in understanding, it is not surprising that the lay press and political pundits have focused on the "miracles of therapy," the wonder drugs, that, unbeknownst to them, have emanated from the hard work and insights of physician-scientists and the clever intervention of the pharmaceutical industry. The fact that the term "miracle drug" is used at all implies not a scientific process of discovery, but rather some serendipitous event, like the "discovery" of penicillin from a laboratory accident. It should come as no surprise to us that while our society wants prevention and cures, they have no understanding of how, or by whom, they are achieved.

Good science is strengthened by vigorous debate, but public understanding of some research topics can be distorted by external influences, political and otherwise, making it even harder to muster support for research investment. We find ourselves less effective than in the past in seeking to bolster political support for commitment to medical research in Washington.

I would like to focus on the public perception of our activities. I have the pleasure of serving on the board of Research!America whose polls have been enlightening, but at times discouraging: The good news is that more than two-thirds of the public believe we should be spending more money on biomedical research (2). In contrast, less than $10 \%$ of Americans can name a biomedical research facility in their area (2). Even worse, two-thirds of Congressional staffers do not know where NIH dollars go and how they are spent (3). Who can we blame for this appalling lack of understanding of the investment in biomedical research? We have to take much of the blame. Most in my generation of physician-scientists have grown up thinking it was self-promoting and unseemly to talk to the press about scientific discovery. Look at the rebuke Carl Sagan took for "popularizing” science in books and television. Journalists, put off by us, are thus unarmed when they attempt to write objectively about science. As noted by Cristine Russell, President of the Council for the Advancement of Science Writing, journalists often approach science stories like any other news story. "They present two sides to every argument, giving the impression that there is a balanced debate about science, when, in fact, equal time, space, or credibility is given to a minority point of view" (4). The National Association of Science Writers Field Guide states that, "More than in any other field of reporting, balance in science writing requires something other than just providing an equal number of column inches to quotes from each side. Balance in science writing requires authorial guidance; it requires context, and knowing when certain points of view simply need to be ignored" (5).

In a 2005 analysis of attitudes about evolution in 33 European and Asian countries and the United States, Miller et al. (6) documented the public acceptance of evolution. Of the 34 countries sampled, the United States ranked 33rd in those answering "true" to the following question: "Human beings, as we know them, developed from earlier species of animals." Even worse, the percentage of US adults accepting the idea of evolution has declined from $45 \%$ to
$40 \%$ on the last 20 years. These results were explained by the influence of fundamentalist religions in the US on attitudes toward evolution (nearly twice as large in the US as in Europe), and the fact that evolution has been politicized and incorporated into partisan politics here, but not observed in Europe or Asia. The broad public acceptance of the benefits of science and technology in the last 50 years, which allowed science to develop a nonpartisan identification, has now ended.

These are troubling results for all of us in science and medicine. Long-term solutions will require a rigorous science education overhaul beginning with young and inquisitive children. The good news is that there is a growing awareness among educators and communicators of science as to this need, with science communication a growing area of practice and research (7). A recent perspective defined science communication as the use of appropriate skills, media, activities and dialogue to produce one or more of the following personal responses to science: awareness, enjoyment, interest, opinion-forming, and understanding (7).

We all need to invest ourselves in this mission. First, we must make education of the public about science an equal priority with the education of the physician-scientist. Second, we must let our trainees know that it is not only all right to educate the press, but a responsibility. Third, we must equip our trainees with the skills to articulate their work not only to their peers, but to the lay public. Scientific progress will be diminished if we do not achieve a more informed dialog with society. We owe our patients nothing less.

1. Science. 2005 Jul 1; 309(5731).

2. Research!America Poll Data. Available at: http:// www.researchamerica.org/polldata/index.html.

3. What Americans Say About the Nation's Medical Schools and Teaching Hospitals. 2004. Report III Key Findings. Public and Congressional Staff Opinion Research Project. Association of American Medical Colleges.

4. Russell, Cristine. 2006. Covering Controversial Science: Improving Reporting on Science and Public Policy. Joan Shorenstein Center on the Press, Politics, and Public Policy Working Paper Series. Available at: http://www.ksg.harvard. edu/presspol/research_publications/papers/ working_papers/2006_4.pdf.

5. Blum, D., Knudson, M., and Marantz Henig, R. 2006. A Field Guide for Science Writers. 2nd edition. The Official Guide of the National Association of Science Writers. Oxford University Press. New York, New York, USA. p. vii.

6. Miller, J.D., Scott, E.C., and Okamoto, S. 2007. Public Acceptance of Evolution. Science. 313:765-766.

7. Burns, T.W., O'Connor, D.J., and Stocklmayer, S.M. 2003. Science Communication: A Contemporary Definition. Public Understanding of Science. 12:183. 